\title{
Prospects for Blockchain Implementation in the Financial Sector
}

\author{
L.A. Petrova ${ }^{1, *}$, O.A. Kalachev ${ }^{2}$, T.E. Kuznetzova ${ }^{1}$, B.S. Saparova ${ }^{3}$ \\ ${ }^{1}$ Digital Economy department, Penza State University, Penza, Russia \\ ${ }^{2}$ Penza Department № 8624 PJSC of "Sberbank of Russia", Penza, Russia \\ ${ }^{3}$ Finance department, L.N. Gumilyov Eurasian National University, Astana, Kazakhstan \\ *Corresponding author. Email: lyu-c@yandex.ru
}

\begin{abstract}
The topic of this article is implementation of blockchain technology in all sectors of the economy, infrastructure, and government system. In recent years, introduction of blockchain was perceived as a revolution in business aimed at making information transfers from one device to another smoother, which significantly reduces the cost: the amount of time, money, human capital etc. Since the launch of blockchain eleven years ago companies, regulators and banks have been actively exploring its potential. The innovation resulted in restructuring of many business processes. The main goal of the research is to analyze the prospects of blockchain development in various elements of economy. Methodologically the research is based on systematic approach. Analysis and synthesis have been used. The article weighs advantages and disadvantages of blockchain and analyzes the prospects for its development. The consensus is that using blockchain in modern economy is essential. We understand that financial community`s future is using information technology for data processing. But blockchain`s weaknesses in terms of protecting personal data are concerning. No centralized operators or administrators are involved in blockchain. The system is managed by all participants peer - to - peer, which means that each blockchain member will ultimately be responsible for personal data control and other personal data developers.
\end{abstract}

Keywords: blockchain, bitcoin, credit, hash function, distributed information storage, public key encryption,

fiat money

\section{INTRODUCTION}

The word "credit" originated from Latin verb "credo" - to believe, trust. However, it is the lack of trust in financial transactions between people that was one of the key prerequisites for banking industry. Risk assessment would be much simpler, often unnecessary, if we could quickly verify the information provided by borrower. Legal procedures related to processing loans and money transfers would be greatly simplified if funds could be automatically returned in case of violation of obligations by the other party to the transaction.

Blockchain technology is used for creating databases that guarantee transparency and verification of the information contained in them. Initially, the technology was a mediator of the private electronic currency Bitcoin, it stored transaction data. The bitcoin system was created by a private initiative of computer enthusiasts with no support from banks or the state. Therefore the technology initially did not provide for ensuring trust through the issuer's assets, which is standard for a regular currency. Blockchain guaranteed the stability of the new currency even in the absence of assets. Firstly, no one can print more money than established by the rules of the system.
Secondly, no one can fake bitcoin transactions as the entire transaction history is stored in a distributed manner and can be fully verified.

Blockchain is a relatively new trend and retains a halo of mystery (fig. 1).

1990 How to build a PC

2000 How to create your own website

2010 How to create Facebook

2018 How to create your own blockchain

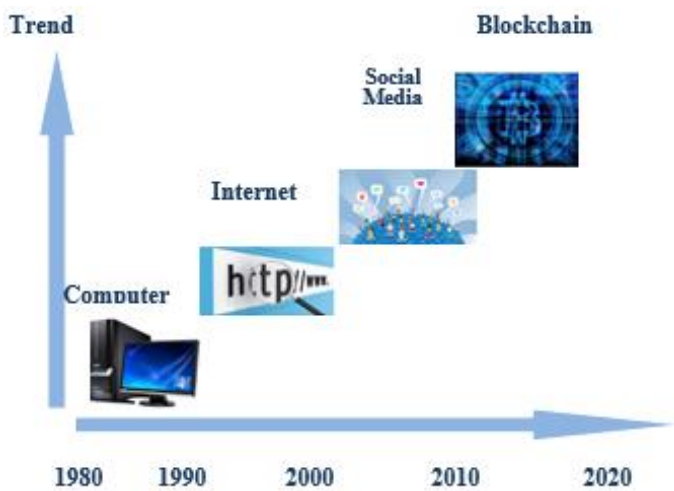

Figure 1. Information and technological changes in society $[1,2]$ 
same. In other words, this output is a unique identifier of the processed information.

Asymmetric encryption means that each transaction participant has a pair of keys that are used both for encryption and electronic signature. These are the socalled public and private key. The public key is freely distributed while the private key is kept secret by the owner of the key pair. It is the private key that the participant uses, both for signing messages and for decrypting them. Other network participants use the public key to verify owner`s electronic signature or to send him an encrypted message that can be decrypted with his private key.

This very asymmetric cryptography`s characteristic, namely the ability to create and verify an electronic signature for any transaction participant, guarantees blockchain`s security. As for the hash function, it is used to identify data blocks, and therefore, link them into a chain.

Asymmetric encryption for signing data ensures its cohesiveness and binds transaction account balances to their owners. As you can see, conceptual blockchain is not something incredibly complex.

However, its implementation is significantly behind compared to traditional databases in terms of speed and convenience.

For example, the pioneer of blockchain, the bitcoin system, can perform only 7 transactions per second [8].

For comparison, Pay Pal performs 450 transactions per second, Visa - 56,000.

The second most popular blockchain platform after Bitcoin is Ethirium. It carries out only 20 transactions per second [8].

Blockchain technology can be used in three fundamental areas.

The first is the automatic verification of transactions and any other information (fig. 2). massive information and outputs some figure of a smal fixed length, for example, 16 or 32 bytes. The output is always constant granted the input information remains the

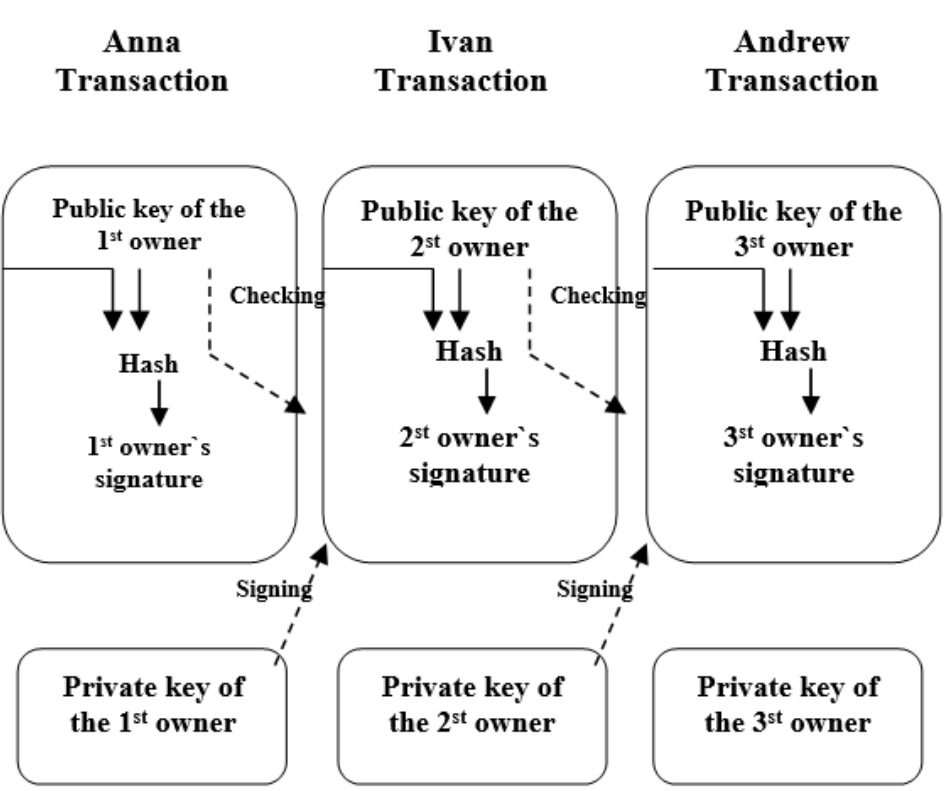

Figure 2. An example of bill of exchange scheme using technology - blockchain $[6,7]$ 
and maintenance. It goes without saying, the shift to a new level will require time and analytical costs, however, this investment will yield a positive return through increased efficiency and reduced costs, which, in turn, will lead to even greater interest in technology, its financing and development [12].

As for legislation, Bank of Russia is creating rich soil for innovations and, together with market participants, is developing relevant legislative norms, considering the interests of both parties. At the end of 2016, the Central Bank established the FinTech Association of state's largest financial institutions. The Association aims at improving regulatory standards and developing effective solutions for the use of advanced financial technologies in Russian market, such open banking API, blockchain and remote identification [3].

The Central Bank is actively creating suitable environment for digital sector development (fig. 4). In April 2018 it launched "regulatory sandbox", a special platform where market participants can test new financial technologies and business models without violating the law. While carrying out "Guidelines for 2018-2020 Financial Technologies Development" the Central Bank will make recommendations for market participants on RegTech technologies implementation to increase the effectiveness of regulatory requirements and risk management, as well as guidelines for SupTech technologies, a supervisory performance booster. Within the same initiative a prototype marketplace is already being developed. It will combine platforms for financial transactions, bots, used by customers to select services, and showcase information on financial services.

Figure 4. Blockchain usage in public and private financial Russian sectors

\subsection{Blockchain implementation in other countries}

Clearing in financial market seems to be the most obvious blockchain implementation. In 2015 Spanish Bank Santander estimated potential savings from reduced cost of clearing at $\$ 20$ billion [13].

We observe increased competition in cryptocurrency transaction processing. The competition draws attention to blockchain and cryptocurrencies by placing start-up companies that rely heavily on these new technologies against a long-established group advocating for radical changes.

Among such startup companies is the international cryptocurrency exchange Ripple, a California-based company established in 2012. It promises to make payments faster, cheaper and more reliable using blockchain [13].

Swift, an interbank message service with 45 years of experience processes half of the world's biggest transactions, it's a cooperative owned by thousands of member banks.

In April 2018 Ripple teamed up with Santander to launch services based on its blockchain messaging software, which will enable Spanish bank customers to send 
blockchain will be problematic. The difficulties are related to data protection in the framework of this technology, since accommodating all 11 thousand member banks requires building more than 100 thousand sub-books. One of the drawbacks of blockchain is its scale. Banks have only implemented blockchain for either internal or bilateral projects between banks.

Ripple solved this problem three years ago, connecting banks "point to point as if online", so that only directly participating banks could see the details of transactions.

However, there is another problem we face when talking about cryptocurrencies, which is high volatility. Several groups are involved in resolving this issue and are working on so-called tokens secured by fiat currency on deposit at central banks.

Examples of such developments are Saga token, launched by a group of economists, including Jacob Frenkel and Myron Scholes and the fact that three Princeton University graduates managed to raise $\$ 133$ million from investors to create collateral for the currency. These attempts are aimed at mitigating the cryptocurrency volatility $[14,15]$.

These events, however, do not eliminate competition between Ripple and Swift. The struggle of blockchain technology in international payments has just begun (table1).

After Swift had tested blockchain with 34 banks, the company stated achieving the required scale with

Table 1. Projects implemented on blockchain in financial sector in different countries [1]

\begin{tabular}{|c|c|c|}
\hline Initiator of the project (country) & Summary of the project & Status of realization \\
\hline 1 & 2 & 3 \\
\hline $\begin{array}{l}\text { MasterCard International Incorporated } \\
\text { (USA) }\end{array}$ & $\begin{array}{l}\text { Creating a database based on blockchain } \\
\text { technology for instant payment processing }\end{array}$ & $\begin{array}{l}\text { Application for project } \\
\text { implementation } \\
\text { (November 2017) }\end{array}$ \\
\hline Plastic card operator Visa & $\begin{array}{l}\text { Launch of the payment service of Visa payment } \\
\text { system on the blockchain }\end{array}$ & Implemented (in test mode) \\
\hline $\begin{array}{c}\text { State Bank of India (SBI) } \\
\text { बैंक ऑफ़ इंडिया } \\
\text { Bank of India }\end{array}$ & $\begin{array}{l}\text { Implementing blockchain-based applications for } \\
\text { smart contracts and KYC procedures }\end{array}$ & In progress \\
\hline $\begin{array}{l}\text { Fidor Bank AG, AG stock exchange for } \\
\text { Kraken (digital currency) }\end{array}$ & $\begin{array}{l}\text { Organization of interaction between Fidor Bank } \\
\text { AG and the Kraken virtual currency exchange in } \\
\text { order to provide German citizens with access to } \\
\text { all major operations with digital currencies }\end{array}$ & Implemented \\
\hline $\begin{array}{l}\text { Bitcoin start-up Coinfenne } \\
\text { (Spain) }\end{array}$ & $\begin{array}{l}\text { Organization of gambling establishments with } \\
\text { Bitcoin }\end{array}$ & Implemented \\
\hline 1 & 2 & 3 \\
\hline 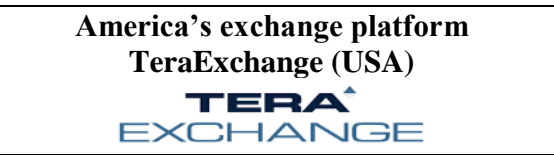 & $\begin{array}{l}\text { Creation of the first regulated Blockchain } \\
\text { platform for derivatives and spot price index for } \\
\text { Bitcoin cryptocurrency }\end{array}$ & Implemented \\
\hline R3 (USA) & $\begin{array}{l}\text { Creation of Corda platform based on blockchain } \\
\text { technology }\end{array}$ & Implemented \\
\hline $\begin{array}{l}\text { French Association of } \\
\text { Insurers Stratumn }\end{array}$ & $\begin{array}{l}\text { The use of Blockchain in the rationalization of } \\
\text { notifications about the insurance industry in } \\
\text { accordance with applicable law (Hamon Law), } \\
\text { which regulates relations arising in connection } \\
\text { with the provision of consumer credit. }\end{array}$ & $\begin{array}{l}\text { in progress (testing of the project } \\
\text { was successful in November 2017) }\end{array}$ \\
\hline
\end{tabular}


[9] Moeckel Caroline «From user-centred design to security: building attacker personas for digital banking» Proceedings of the 10th Nordic conference on humancomputer interaction. Pp. 892-897 (2018).

[10] Albion Murati, Oskar Skau, Zubin Taraporevala and another. «Disruption in European consumer finance: Lessons from Sweden. Global Banking» Developing a digital banking framework in the Iranian banks: prerequisites and facilitators. International journal of ebusiness research, 14, 4, pp. 65-77 (2018).

[11] Mbama Cajetan I., Ezepue Patrick O. «Digital banking, customer experience and bank financial performance: UK customers' perceptions» International journal of bank marketing, 36, 2, pp. 230-255 (2018).

[12] Program of digital economy development in the Russian Federation till 2035. URL: https:// www.static.government.ru , last accessed 02.12.2019.

[13] E. P. Ermakova , E. E. Frolova. «Legal regulation of digital. Banking in Russia and foreign countries») Eeuropean union, usa, prc, 4, 606-625 (2019).

[14] Lutchenko V.G., Khorev A.I., Khorev I.A., Grigoryeva V.V. «Analysis of factors affecting labor productivity» Proceedings of the Voronezh State University of Engineering Technologies. 2019; 81(3):368374. (In Russ.)https://doi.org/10.20914/2310-1202-20193-368-374

[15] Serebryakova N.A., Avdeev I.V. «The content of structural transformations of the region's economy, adequate to the requirements of digitalization» Proceedings of the Voronezh State University of Engineering Technologies. 2018; 80(4):408412. (In Russ.) https://doi.org/10.20914/2310-1202-20184-408-412

[8] Mujinga Mathias, Eloff Mariki M., Kroeze Jan H. «System usability scale evaluation of online banking services: A South African study» South African journal of science, 114, 3-4 (2018). 